\title{
Microstructure and formation conditions of the reddish hi-iro marking on traditional Japanese ceramics
}

\author{
Yoshihiro KUSANO, ${ }^{\dagger}$ Teruaki DANNO, ${ }^{*}$ Keiko TOKUNAGA, ${ }^{* *}$ Nobuaki KAMOCHI, ${ }^{* * *}$ \\ Hideki HASHIMOTO, ${ }^{*}$ Makoto NAKANISHI, ${ }^{*}$ Tatsuo FUJII, ${ }^{*}$ \\ Minoru FUKUHARA ${ }^{* * * *}$ and Jun TAKADA* \\ Department of Fine and Applied Arts, College of the Arts, Kurashiki University of Science and the Arts, \\ 2640 Nishinoura, Tsurajima-cho, Kurashiki, Okayama 712-8505 \\ *Graduate School of Natural Science and Technology, Okayama University, \\ 3-1-1 Tsushima-naka, Kita-ku, Okayama 700-8530 \\ ** Department of Applied Chemistry, Faculty of Engineering, Okayama University, \\ 3-1-1 Tsushima-naka, Kita-ku, Okayama 700-8530 \\ ${ }^{* * *}$ Saga Ceramies Research Laboratory, 3037-7 Kuromuta, Arita-cho, Nishimatsuura-gun, Saga 844-0022 \\ **** Department of Applied Chemistry and Biotechnology, Faculty of Engineering, Okayama University of Science, \\ 1-1 Ridai-cho, Kita-ku, Okayama 700-0005
}

The microstructure and conditions for the formation of the reddish color referred to as hi-iro on Japanese ceramics were investigated through model experiments. The hi-iro marking was found to be formed by the reaction between clay and alkali ions supplied from the glaze. When a mixture of porcelain clay and $20 \mathrm{wt} \% \mathrm{KCl}$ was heated in air at $1250^{\circ} \mathrm{C}$ and then cooled slowly to $8^{\circ}{ }^{\circ} \mathrm{C}$, hi-iro clearly appeared on the sample surface. In hi-iro, corundum $\left[\alpha-(\mathrm{Al}, \mathrm{Fe})_{2} \mathrm{O}_{3}\right]$, hematite $\left(\alpha-\mathrm{Fe}_{2} \mathrm{O}_{3}\right)$ and a liquid phase are formed. Upon heating until $1^{250}{ }^{\circ} \mathrm{C}$, corundum is firstly precipitated as hexagonal plate-like crystals. During the cooling process, hematite precipitates on the edges of the corundum crystals to form specific composite particles. When rapidly cooled from $1250^{\circ} \mathrm{C}$ to room temperature, a brownish red color appeared on the sample surface, which was found to be caused by the formation of approximately $50 \mu \mathrm{m}$ Al-substituted hematite $\left(\mathrm{Fe}_{1.9} \mathrm{Al}_{0.1} \mathrm{O}_{3}\right)$ particles. The relationship between the microstructure of the phases formed and the color is discussed.

(C2011 The Ceramic Society of Japan. All rights reserved.

Key-words : Traditional ceramics, Reddish color, Microstructure, Hematite, Corundum, Hi-iro

[Received May 30, 2011; Accepted September 29, 2011]

\section{Introduction}

There have been many studies regarding starting materials used in the production of pottery and porcelain, such as clay, glaze, and pigments; ${ }^{1)-4)}$ however, there have been very few studies of the patterns formed on the products. This is most likely because there are many parameters, such as the chemical composition of the clay, firing temperature, heating and cooling rates, and effective oxygen partial pressure involved in the firing process. However, we believe that much interesting chemistry remains hidden in the traditional technologies and arts.

We have previously reported a mechanism for the formation of the reddish hidasuki pattern on Bizen stoneware. ${ }^{5)-11)}$ Firstly, corundum $\left(\alpha-\mathrm{Al}_{2} \mathrm{O}_{3}\right)$ is precipitated as hexagonal plate-like crystals above $1100^{\circ} \mathrm{C}$ in a liquid phase formed by the reaction between potassium in rice straw and Bizen clay containing approximately $2-3 \mathrm{wt} \% \mathrm{Fe}_{2} \mathrm{O}_{3}{ }^{12)}$ Secondly, hematite $\left(\alpha-\mathrm{Fe}_{2} \mathrm{O}_{3}\right)$ is grown epitaxially on the edges of these crystals during cooling after heating at $1250^{\circ} \mathrm{C}$. Hematite covers the corundum crystals to form a specific composite of $\alpha-\mathrm{Fe}_{2} \mathrm{O}_{3} / \alpha-\mathrm{Al}_{2} \mathrm{O}_{3} / \alpha-\mathrm{Fe}_{2} \mathrm{O}_{3}$ sandwich-like particles. In addition, the artificial reproduction of hidasuki was demonstrated using potassium chloride instead of rice straw.

$\uparrow$ Corresponding author: Y. Kusano; E-mail: yoshi-k@arts.kusa. ac.jp
Occasionally, a reddish marking known as hi-iro appears on pottery and porcelain, even when the starting clay has a low iron content and is heated without rice straw. This pattern seems to be produced by the same mechanism as that for hidasuki, ${ }^{8)}$ although the details of hi-iro formation have yet to be clarified. Here the microstructural features and mechanism for the formation of hi-iro are reported from the results of model experiments.

\section{Experimental procedure}

The dried porcelain clay starting material, of which the chemical composition is given in Table 1, was ground and pelletized to form a green body $20 \mathrm{~mm}$ in diameter and approximately $2 \mathrm{~mm}$ thick. Ground potassium chloride $(\mathrm{KCl}$, reagent grade, $0.1 \mathrm{~g}$ ) was also formed into a pellet $15 \mathrm{~mm}$ in diameter and approximately $0.4 \mathrm{~mm}$ thick, and placed on the clay pellet. Clay pellets, with and without $\mathrm{KCl}$ pellets were heated to $1250^{\circ} \mathrm{C}$ at a rate of $5^{\circ} \mathrm{C} / \mathrm{min}$ in air and held for $15 \mathrm{~min}$. This temperature is close to that utilized in actual kilns. The samples were quenched or cooled to $800^{\circ} \mathrm{C}$ at different rates $\left(1-37^{\circ} \mathrm{C} /\right.$ $\mathrm{min}$ ) and then rapidly cooled to room temperature. Mixtures of

Table 1. Chemical composition of porcelain clay (wt \%)

\begin{tabular}{cccccccc}
\hline $\mathrm{SiO}_{2}$ & $\mathrm{Al}_{2} \mathrm{O}_{3}$ & $\mathrm{TiO}_{2}$ & $\mathrm{Fe}_{2} \mathrm{O}_{3}$ & $\mathrm{CaO}$ & $\mathrm{MgO}$ & $\mathrm{K}_{2} \mathrm{O}$ & $\mathrm{Na}_{2} \mathrm{O}$ \\
\hline 73.2 & 20.7 & 0.19 & 0.52 & 0.37 & 0.14 & 4.03 & 0.65 \\
\hline
\end{tabular}




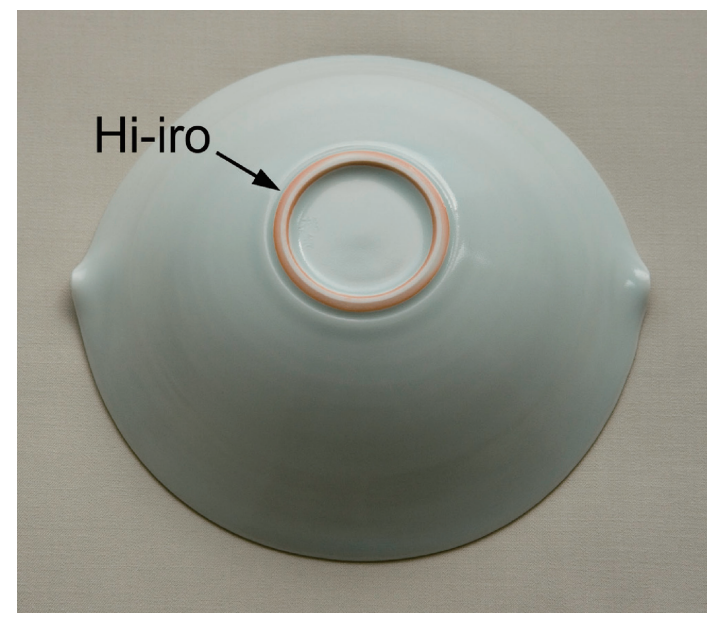

Fig. 1. Typical reddish hi-iro marking on the foot of a celadon bowl.

clay and $\mathrm{KCl}(10-40 \mathrm{wt} \% \mathrm{KCl}$ in the mixture) were also formed into pellets $15 \mathrm{~mm}$ in diameter and approximately $1.6 \mathrm{~mm}$ thick, and then heated using the same heating process. The chemical composition of the clay was analyzed using X-ray fluorescence spectroscopy (XFS; Rigaku RIX2100). The crystalline phases formed on the as-prepared pellet surfaces were identified using powder X-ray diffraction (XRD; Rigaku Rint2100, $\mathrm{CuK} \alpha$ radiation). Microstructural observations were conducted using transmission electron microscopy [TEM; Topcon EM-002B, Jeol JEM-4000EX and JEM-2100F with a Cs-corrector (CEOS) and energy-dispersive X-ray analysis (EDS)] and scanning electron microscopy (SEM; Jeol JSM-6490). As reported in a previous paper, crystals are embedded in the glassy phase $;^{8)}$ therefore, the samples for TEM and SEM were prepared by treating the surface of a pellet with $47 \%$ hydrofluoric acid for $15 \mathrm{~s}$ to $2 \mathrm{~min}$ to remove the glassy phase. For TEM, the crystals were then dispersed in carbon tetrachloride by ultrasonication and collected on a microgrid. The colors of the sample surface were measured using a colorimeter with a standard illuminant of $\mathrm{D}_{65}$ (CM-2600d, Konica Minolta Sensing, Inc.). Mössbauer spectra of the asprepared sample surfaces or fragments scraped from the sample surface were obtained at room temperature.

\section{Results and discussion}

The typical reddish marking known as hi-iro on the foot of a commercial celadon bowl is shown in Fig. 1. This reddish marking is frequently observed on unglazed bodies close to the glazed part, as shown in the figure. It is thought that the turquoise blue of celadon is generally caused by ferrous ions in a glassy phase. On the other hand, it is obvious that the reddish color of hi-iro results from ferric ions. ${ }^{13)}$

To clarify the microstructure of hi-iro formation, SEM and TEM observations of hi-iro on celadon were performed, and representative images are shown in Fig. 2. The sample for the TEM observations was obtained from light reddish part of hi-iro. The stick-like particles are mullite crystals $\left(\mathrm{Al}_{6} \mathrm{Si}_{2} \mathrm{O}_{13}\right)$, which is formed by the heat treatments in traditional ceramics, that function as a framework. The large hexagonal plate-like particles approximately $\sim 3.0 \mu \mathrm{m}$ in width (Fig. 2) were identified as corundum by EDS and electron diffraction (ED; inset in Fig. 2). This phase is usually assumed to have hexagonal rod-like crystals, but can form hexagonal plate-like crystals when synthesized in the presence of additional elements such as $\mathrm{Si}, \mathrm{Ca}, \mathrm{Mg}$, and $\mathrm{Na},{ }^{14)-17)}$ which are all present in commonly
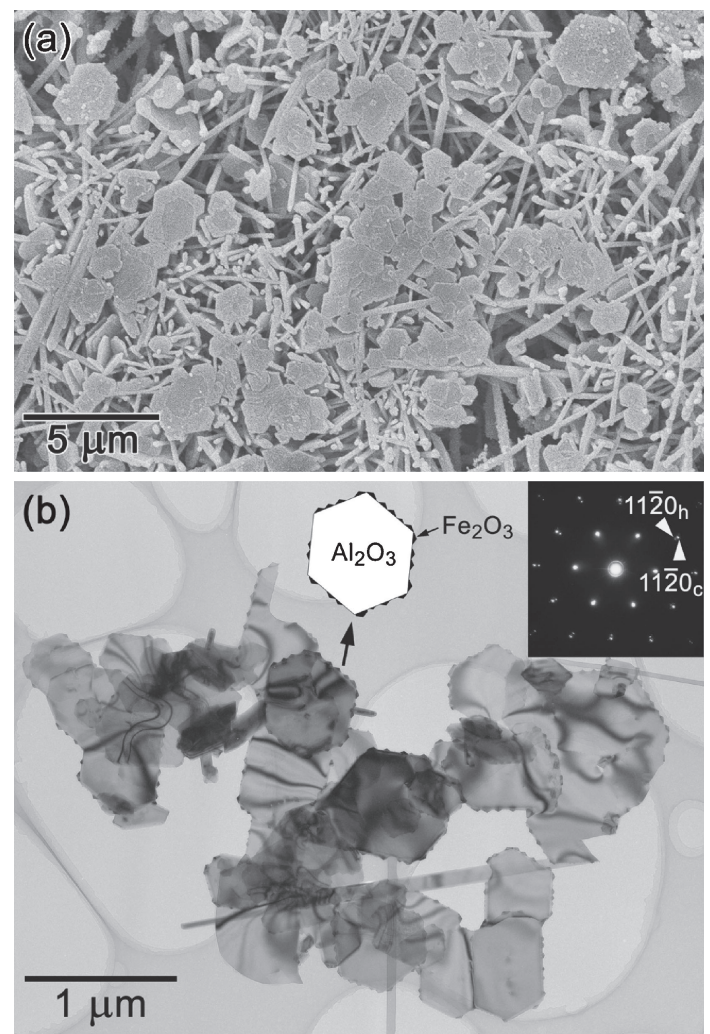

Fig. 2. Typical (a) SEM image of the surface of hi-iro on celadon and (b) TEM image of crystals obtained from hi-iro. The schematic illustration indicates the relationship between hematite and corundum. The [0001] ED pattern (inset) of the phases indicates the epitaxial growth of hematite on corundum (c: corundum and h: hematite).

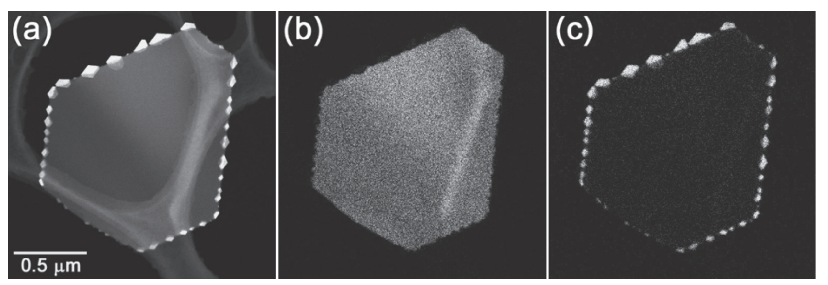

Fig. 3. (a) HAADF-STEM image of a crystal formed in hi-iro, and (b) $\mathrm{Al}$ and (c) Fe map images.

used clay. Fine particles of approximately $0.1 \mu \mathrm{m}$ in size were precipitated on the edges of the corundum particles, as schematically illustrated in Fig. 2. These fine particles were identified as hematite by EDS and ED measurements. The ED pattern in the inset indicates hexagonal symmetry with growth that proceeded preferentially in the basal planes. Moreover, both crystal directions are the same, which indicates an epitaxial relationship between the two phases. It seems that hi-iro is colored by the precipitation of hematite on corundum crystals, as reported for reddish hidasuki on Bizen stoneware. ${ }^{5)-8), 11)}$

It is well known that corundum forms a solid solution of $\mathrm{Al}_{2-x} \mathrm{Fe}_{x} \mathrm{O}_{3}(x \leq 0.18)$ at $1250^{\circ} \mathrm{C}^{18)}$ and that this solid solution has an ocherous appearance. This phase is also probably involved in the hi-iro coloring. Analytical TEM observations were conducted to confirm this. Figure 3 shows a high-angle annular dark-field scanning-TEM (HAADF-STEM) image (a) of a crystal formed in hi-iro with mapping images for (b) $\mathrm{Al}$ and (c) Fe. Figure 3(b) confirms that aluminum is not incorporated into the 


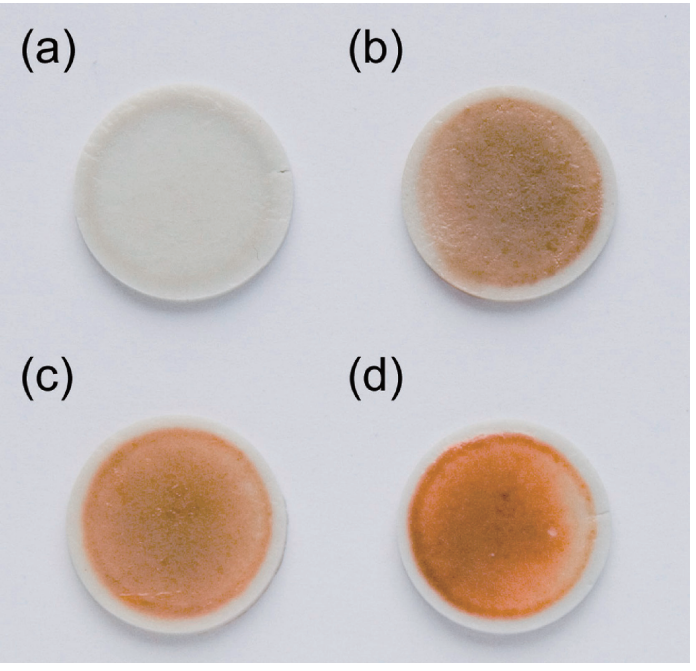

Fig. 4. Typical colors of sample surfaces covered by $\mathrm{KCl}$ pellets, heated at $1250^{\circ} \mathrm{C}$ for $15 \mathrm{~min}$ and then (a) quenched $(\mathrm{K} / \mathrm{Q})$ or cooled to $800^{\circ} \mathrm{C}$ at a rate of (b) $37(\mathrm{~K} / 37)$, (c) $10(\mathrm{~K} / 10)$ and (d) $1{ }^{\circ} \mathrm{C} / \mathrm{min}(\mathrm{K} / 1)$ in air

outer fine hematite particles. However, the corundum was found to contain approximately $4 \mathrm{~mol} \% \mathrm{Fe}$, which indicates that the chemical composition of this corundum is $\mathrm{Al}_{1.92} \mathrm{Fe}_{0.08} \mathrm{O}_{3}$. The solid solution with a nominal composition of $\mathrm{Al}_{1.92} \mathrm{Fe}_{0.08} \mathrm{O}_{3}$ prepared in this study from $\mathrm{Al}\left(\mathrm{NO}_{3}\right)_{3} \cdot 9 \mathrm{H}_{2} \mathrm{O}$ and $\mathrm{Fe}\left(\mathrm{NO}_{3}\right)_{3} \cdot 9 \mathrm{H}_{2} \mathrm{O}$ had a lightly ocherous appearance with $L^{*}=84.9, a^{*}=0.8$ and $b^{*}=25.8$. Therefore, it was concluded that the reddish color of hi-iro was caused by the precipitation of hematite and Fe-substituted corundum. Hereafter, we refer to this solid solution as corundum for simplicity.

The slow cooling from 1250 to $800^{\circ} \mathrm{C}$ and the supply of potassium from rice straw are important for the formation of the hidasuki pattern; ${ }^{5)-8), 11)}$ however, in the case of porcelain, no rice straw is used during the heat treatment. Therefore, it is supposed that alkali ions are supplied from the glaze because hi-iro appears on an unglazed part close to glazed part (Fig. 1). Potassium feldspar [for example, orthoclase: $\mathrm{KAlSi}_{3} \mathrm{O}_{8}$ and/or sanidine: $\left.(\mathrm{K}, \mathrm{Na}) \mathrm{AlSi}_{3} \mathrm{O}_{8}\right]$ is commonly used as a raw material for glaze and was thought to be the source of the alkali ions. Preliminary experiment showed that sodium addition lowered the melting point of the clay, and the sample shape was deformed after heat treatment at $1250^{\circ} \mathrm{C}$. In this study, we examined the effect of potassium addition to the porcelain clay on the formation of hi-iro.

Model experiments were conducted to determine the importance of the cooling rates and the presence of alkali ions in hi-iro formation. When the porcelain clay was heated without $\mathrm{KCl}$ at $1250^{\circ} \mathrm{C}$ and then cooled to $800^{\circ} \mathrm{C}$ at a rate of $1{ }^{\circ} \mathrm{C} / \mathrm{min}$ in air, the sample surface had a whitish porcelain color (sample NK/1, not shown). The color of this sample was not dependent on the cooling rate. On the other hand, the surfaces of samples covered with $\mathrm{KCl}$ pellets exhibited a reddish color. Figure 4 shows typical colors of the sample surfaces after heat treatment at $1250^{\circ} \mathrm{C}$ for $15 \mathrm{~min}$ and then quenched (K/Q) or cooled to $800^{\circ} \mathrm{C}$ at a rate of $37(\mathrm{~K} / 37), 10(\mathrm{~K} / 10)$, and $1{ }^{\circ} \mathrm{C} / \mathrm{min}(\mathrm{K} / 1)$ in air. The $L^{*} a^{*} b^{*}$ values of the sample surfaces are summarized in Table 2. The color of the $\mathrm{K} / \mathrm{Q}$ surface was similar to that of the sample heated without a $\mathrm{KCl}$ pellet, although it had a glassy appearance. The samples shown in Figs. 4(b)-4(d) had surfaces with a reddish glaze-like appearance. The color of the sample
Table 2. Color of sample surfaces heated with and without $\mathrm{KCl}$

\begin{tabular}{lccr}
\hline Cooling rate $/{ }^{\circ} \mathrm{C} / \min$ & \multicolumn{3}{c}{$\mathrm{Hue}^{\dagger}$} \\
\cline { 2 - 4 }$($ Sample name) & $L^{*}$ & $a^{*}$ & \multicolumn{1}{c}{$b^{*}$} \\
\hline $1\left(\mathrm{NK} / 1^{\ddagger}\right)$ & 82.7 & -0.7 & 6.1 \\
Quenched $(\mathrm{K} / \mathrm{Q})$ & 80.7 & -1.3 & 9.5 \\
$37(\mathrm{~K} / 37)$ & 56.5 & 11.7 & 28.0 \\
$10(\mathrm{~K} / 10)$ & 54.6 & 15.4 & 28.2 \\
$1(\mathrm{~K} / 1)$ & 54.4 & 18.9 & 31.2 \\
\hline
\end{tabular}

${ }^{\dagger}$ CIE $1976 L^{*} a^{*} b^{*}$ color space. $L^{*}$ indicates lightness, and $a^{*}$ and $b^{*}$ indicate chromaticity, i.e. color directions. Positive and negative values of $a^{*}$ indicate reddish and greenish color, respectively, while positive and negative values of $b^{*}$ indicate yellowish and bluish color, respectively. ${ }^{\ddagger}$ Sample $\mathrm{NK} / 1$ was heated without $\mathrm{KCl}$.

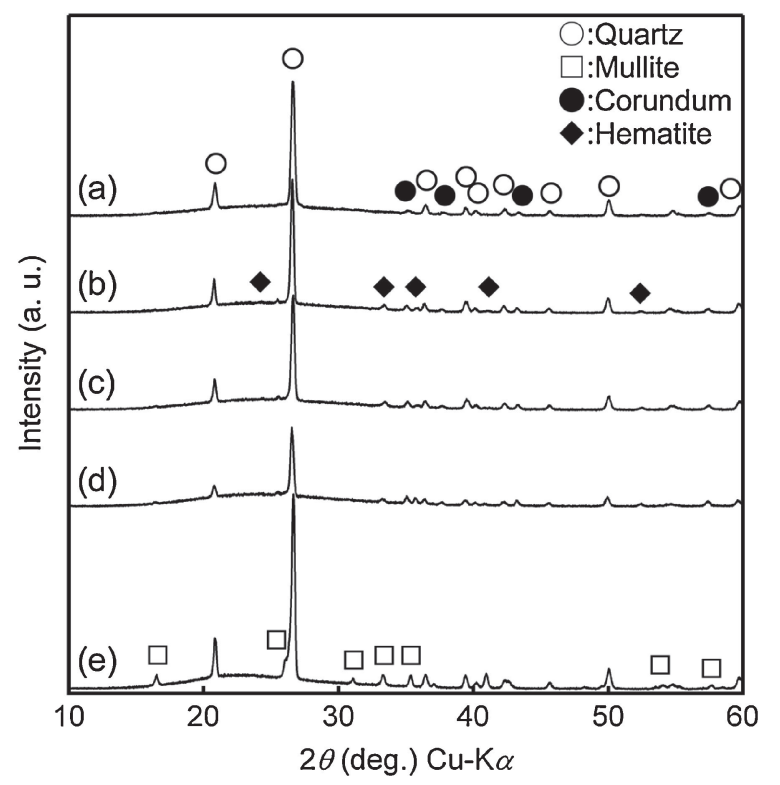

Fig. 5. XRD patterns of the (a) K/Q, (b) $\mathrm{K} / 37$, (c) $\mathrm{K} / 10$, (d) $\mathrm{K} / 1$ and (e) $\mathrm{NK} / 1$ sample surfaces.

surfaces changed from a brownish to reddish color with a decrease in the cooling rate. The reason for this will be discussed later.

XRD patterns of the sample surfaces are shown in Fig. 5 . Sample NK/1 contains mullite and quartz $\left(\mathrm{SiO}_{2}\right)$, which are common phases in traditional ceramics. On the other hand, mullite is absent in the sample surfaces covered by $\mathrm{KCl}$ pellets [Figs. 5(a)-5(d)], and a small amount of corundum and hematite is evident. The corundum formation in the liquid phase is a key in the formation of hematite. The intensity of the corundum and hematite peaks increased slightly as the cooling rate was decreased, which resulted in the color becoming more reddish.

TEM images of the crystals formed in the glassy phase of the (a) K/37 and (b) K/1 surfaces are shown in Fig. 6. The K/37 surface has the same microstructure as that shown in Fig. 2. The ED pattern shown in the inset of Fig. 6(a) indicates that hematite was grown epitaxially on corundum. At the slower cooling rate of $1{ }^{\circ} \mathrm{C} / \mathrm{min}$, the hematite crystals [dark particles labeled $\mathrm{Fe}_{2} \mathrm{O}_{3}$ in Fig. 6(b)] grew larger. The color tone of the sample surfaces was found to be affected by the cooling rate, similar to the hidasuki pattern on Bizen stoneware. ${ }^{5)-8), 11)}$

The relationship between the amount of $\mathrm{KCl}$ in the porcelain clay $/ \mathrm{KCl}$ mixture and the color of the pellets was considered. The colors of mixtures of clay and $10-30 \mathrm{wt} \% \mathrm{KCl}$ heated at 

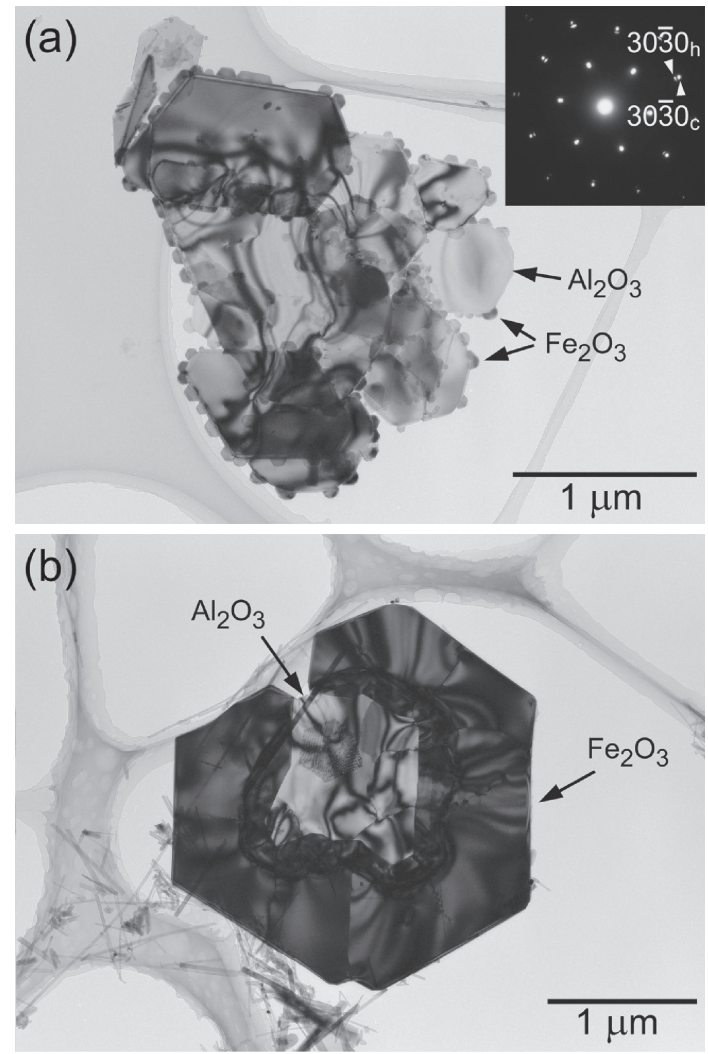

Fig. 6. TEM images of crystals formed on the (a) K/37 and (b) $K / 1$ surfaces. The morphology of the corundum and hematite crystals and their crystallographic relationship as shown in (a) is the same as that of celadon shown in Fig. 2. The size of the hematite crystals increased as the cooling rate was decreased.

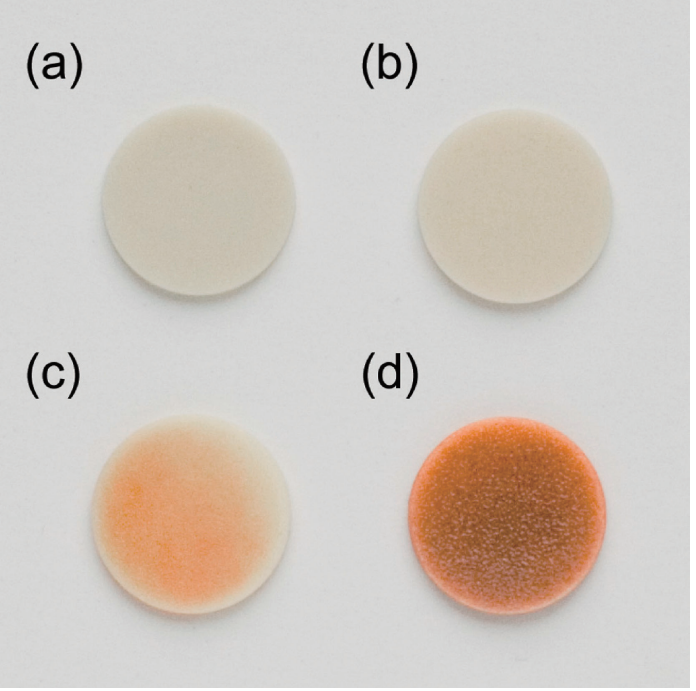

Fig. 7. Typical colors of mixtures of clay and $\mathrm{KCl}$ at (a) 10 (10.9), (b) 15 (14.2), (c) $20(17.7)$, and (d) $30 \mathrm{wt} \%(25.0 \mathrm{wt} \%)$, heated at $1250^{\circ} \mathrm{C}$ for $15 \mathrm{~min}$ and then cooled to $800^{\circ} \mathrm{C}$ at a rate of $1{ }^{\circ} \mathrm{C} / \mathrm{min}$ in air. The values in parentheses denote the total amount of alkali oxides $\left(\mathrm{K}_{2} \mathrm{O}\right.$ and $\mathrm{Na}_{2} \mathrm{O}$ ) in the mixture of clay and $\mathrm{KCl}$.

$1250^{\circ} \mathrm{C}$ for $15 \mathrm{~min}$ are shown in Fig. 7. The samples were cooled to $800^{\circ} \mathrm{C}$ at a rate of $1{ }^{\circ} \mathrm{C} / \mathrm{min}$ and then rapidly cooled to room temperature. The samples with 10 and $15 \mathrm{wt} \% \mathrm{KCl}$ had a slightly yellowish color, whereas those with 20 and $30 \mathrm{wt} \% \mathrm{KCl}$ had
Table 3. Color of the sample surfaces in Fig. 7

\begin{tabular}{cccc}
\hline \multirow{2}{*}{$\mathrm{KCl}$ content/wt \% } & \multicolumn{3}{c}{ Hue } \\
\cline { 2 - 4 } & $L^{*}$ & $a^{*}$ & $b^{*}$ \\
\hline 10 & 79.8 & -1.5 & 8.8 \\
15 & 80.3 & -0.9 & 10.9 \\
20 & 71.1 & 13.0 & 34.2 \\
30 & 47.6 & 17.5 & 14.6 \\
\hline
\end{tabular}

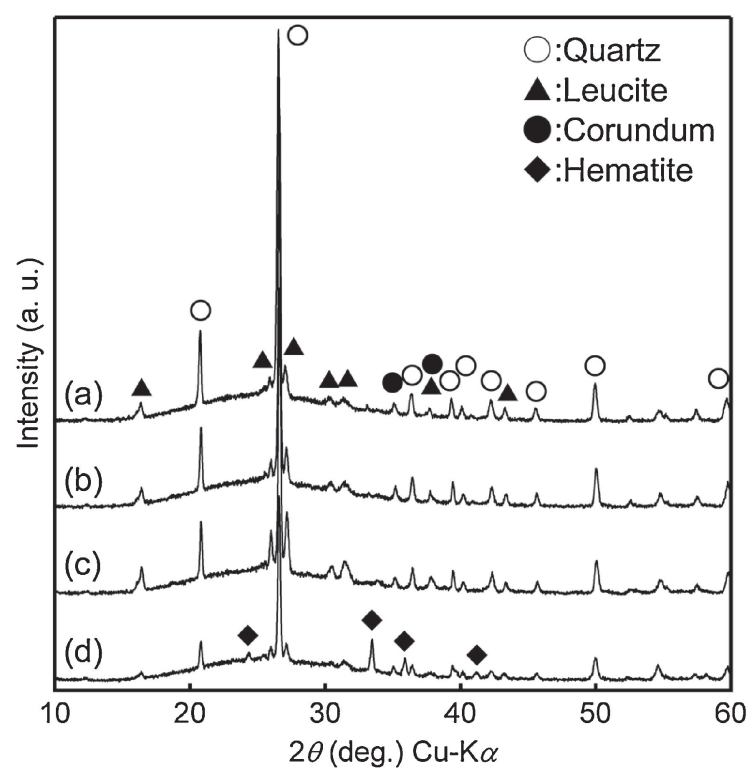

Fig. 8. XRD patterns of the sample surfaces shown in Fig. 7; mixtures of clay and $\mathrm{KCl}$ at (a) 10 (10.9), (b) 15 (14.2), (c) 20 (17.7), and (d) $30 \mathrm{wt} \%(25.0 \mathrm{wt} \%)$, heated at $1250^{\circ} \mathrm{C}$ for $15 \mathrm{~min}$ and then cooled to $800^{\circ} \mathrm{C}$ at a rate of $1^{\circ} \mathrm{C} / \mathrm{min}$ in air.

a distinct reddish color. The $L^{*} a^{*} b^{*}$ values of these sample surfaces are summarized in Table 3. The total alkali oxide $\left(\mathrm{K}_{2} \mathrm{O}\right.$ and $\mathrm{Na}_{2} \mathrm{O}$ ) content in the mixtures with $10,15,20$, and $30 \mathrm{wt} \%$ $\mathrm{KCl}$ were $10.9,14.2,17.7$, and $25.0 \mathrm{wt} \%$, considering the amount of alkali components in the clay of which the chemical composition is shown in Table 1. Summarizing the results, hi-iro appears when the $\mathrm{KCl}$ content exceeds $20 \mathrm{wt} \%$ (17.7 wt \% alkali oxides) in the mixture, which is equivalent to $13.3 \mathrm{~mol} \%$ of the total alkali oxides $\left(\mathrm{K}_{2} \mathrm{O}\right.$ and $\left.\mathrm{Na}_{2} \mathrm{O}\right)$ in the mixture.

XRD patterns of the sample surfaces shown in Fig. 7 are presented in Fig. 8. The XRD pattern of the $0 \mathrm{wt} \% \mathrm{KCl}(\mathrm{NK} / 1)$ sample shown in Fig. 5(e) indicates that mullite is present, although it is absent in all the other sample surfaces; however, leucite $\left(\mathrm{KAlSi}_{2} \mathrm{O}_{6}\right)$, corundum and hematite are present in all samples. The formation of hematite was prominent for the sample prepared with $30 \mathrm{wt} \% \mathrm{KCl}$.

The relationship between the color and microstructure of the $\mathrm{K} / 37$ sample is discussed here. It is well known that the color of hematite changes from yellowish red to black as the particle size is increased. ${ }^{1-3)}$ Assuming that the coloring crystal is hematite grown on corundum, then the surface of $\mathrm{K} / 37$ should have a yellowish red color when cooled rapidly, due to the smaller hematite particle size (approximately $0.1 \mu \mathrm{m}$ ). However, K/37 has a brownish color, as shown in Fig. 4, which suggests the formation of another phase. The inset in Fig. 9(a) shows an optical micrograph of the as-prepared K/37 surface. Large platelike particles approximately $50 \mu \mathrm{m}$ in diameter were found on the glassy phase. The EDS spectrum of the black plate-like particles 
(a)

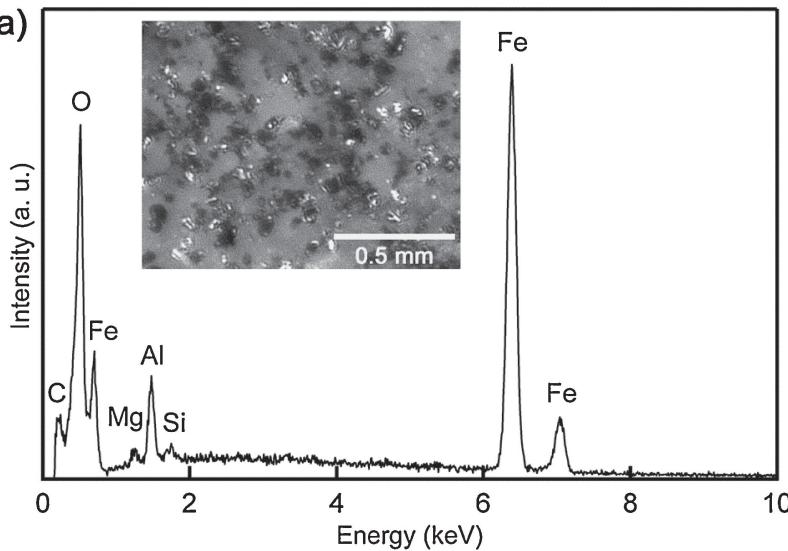

(b)

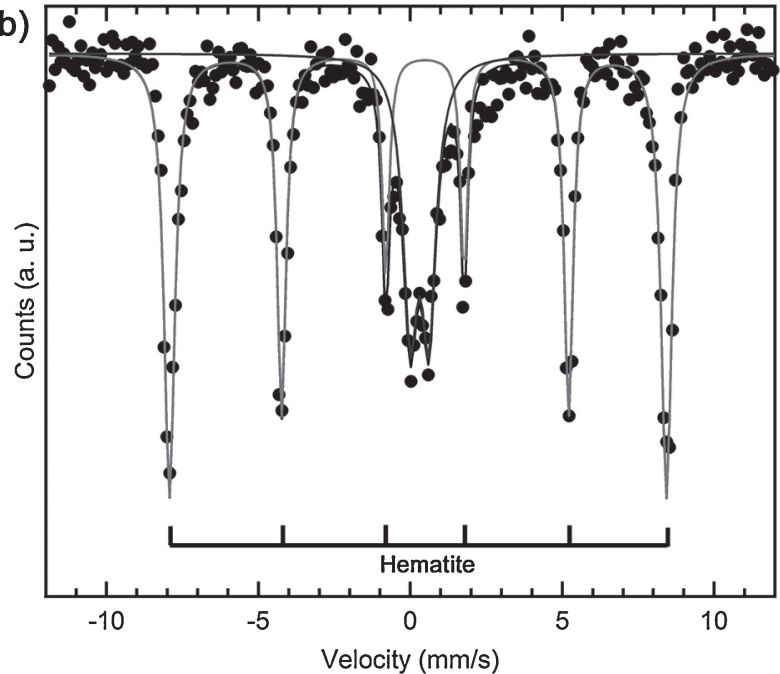

Fig. 9. (a) EDS spectrum of a particle formed on the $\mathrm{K} / 37$ surface and (b) Mössbauer spectrum of powder scraped from the $K / 37$ surface after etching with $47 \%$ hydrofluoric acid for $15 \mathrm{~s}$. The inset in (a) shows an optical micrograph of the as-prepared $\mathrm{K} / 37$ surface. The magnetic component is assigned to hematite.

shown in the inset indicates that this phase consists of mainly $\mathrm{Fe}$, $\mathrm{Al}$ and $\mathrm{O}$ with an $\mathrm{Fe} / \mathrm{Al}$ atomic ratio of $0.95 / 0.05$. Considering the XRD result in Fig. 5(b), these particles are Al-substituted iron oxide. A small amount of $\mathrm{Mg}$ and $\mathrm{Si}$ appears to originate from the glassy phase. A Mössbauer spectrum of the powder scraped from the K/37 surface after etching is shown in Fig. 9(b). A magnetic component assigned to hematite is clearly evident. The paramagnetic component corresponds to $\mathrm{Fe}^{3+}$ in the glassy phase and in corundum; therefore, the plate-like particles in Fig. 9(a) can be identified as $\mathrm{Al}$-substituted hematite, represented as $\mathrm{Fe}_{1.9} \mathrm{Al}_{0.1} \mathrm{O}_{3}$. In summary, the brownish color of the $\mathrm{K} / 37$ surface is a mixed color of the blackish hematite $\left(\mathrm{Fe}_{1.9} \mathrm{Al}_{0.1} \mathrm{O}_{3}\right)$ crystals on the sample surface and the reddish composite particles of hematite on corundum in the glassy phase. Further studies of the formation mechanism of single crystalline hematite are expected to be of significant interest because this phase seems to be related to other crystalline glazes, such as oilspot glaze.

\section{Conclusions}

The microstructure and conditions for the formation of the reddish marking known as hi-iro were investigated using model experiments. The formation mechanism of hi-iro was the same as that for hidasuki formation on Bizen stoneware despite the fact that the iron content in the porcelain clay was $1 / 4-1 / 6$ that of Bizen clay. Namely, the Fe-substituted corundum formation in the liquid phase and the $\mathrm{Fe}^{3+}$ diffusion in the liquid during the cooling process were essential to hi-iro formation. Hi-iro was formed as follows: (1) a liquid phase is formed on the surface by reaction between the clay and mainly potassium supplied by the glaze, (2) Fe-substituted corundum $\left(\alpha-\mathrm{Al}_{1.92} \mathrm{Fe}_{0.08} \mathrm{O}_{3}\right)$ precipitates as hexagonal plate-like crystals in the liquid phase, and then (3) the $\mathrm{Fe}^{3+}$ diffused in the liquid phase and precipitated as hematite $\left(\alpha-\mathrm{Fe}_{2} \mathrm{O}_{3}\right)$ epitaxially on the edges of the Fe-substituted corundum during the cooling process. An effective amount of potassium chloride $(\mathrm{KCl})$ for hi-iro formation was found to be over $20 \mathrm{wt} \%$ in the mixture of porcelain clay and $\mathrm{KCl}$. This value corresponds to a total amount of alkali oxides $\left(\mathrm{K}_{2} \mathrm{O}\right.$ and $\left.\mathrm{Na}_{2} \mathrm{O}\right)$ in the mixture of $17.7 \mathrm{wt} \%$, which is equivalent to $13.3 \mathrm{~mol} \%$ as the total mole fraction of $\mathrm{K}_{2} \mathrm{O}$ and $\mathrm{Na}_{2} \mathrm{O}$ in the mixture. The rapidly cooled sample $\left(37^{\circ} \mathrm{C} / \mathrm{min}\right)$ exhibited a brownish-red color, due to the formation of Al-substituted hematite $(\alpha$ $\mathrm{Fe}_{1.9} \mathrm{Al}_{0.1} \mathrm{O}_{3}$ ) particles of approximately $50 \mu \mathrm{m}$ in diameter on the sample surface.

Acknowledgements We would like to thank Yoshiyasu Kato and Shingo Aoi (Kurashiki University of Science and the Arts) for preparation of the hi-iro samples. This study was supported by Grantin-Aids for Scientific Research (KAKENHI) numbered 21550194.

\section{References}

1) T. Takada, J. Jpn. Soc. Powder Powder Metall., 4, 169-186 (1958).

2) T. Takada and M. Kiyama, J. Jpn. Soc. Powder Powder Metall., 4, 187-192 (1958).

3) H. Katsuki and S. Komarneni, J. Am. Ceram. Soc., 86, 183185 (2003).

4) H. Asaoka, Y. Kusano, M. Nakanishi, T. Fujii and J. Takada, J. Jpn. Soc. Powder Powder Metall., 50, 1062-1067 (2003).

5) K. Yamaguchi, Y. Kusano, M. Fukuhara, A. Doi and T. Takada, J. Jpn. Soc. Powder Powder Metall., 39, 79-85 (1992).

6) K. Yamaguchi, Y. Kusano, M. Fukuhara and A. Doi, J. Jpn. Soc. Powder Powder Metall., 39, 179-183 (1992).

7) M. Fukuhara, M. Fujiwara, K. Yamaguchi and A. Doi, J. Ceram. Soc. Japan, 97, 1420-1423 (1989).

8) Y. Kusano, M. Fukuhara, T. Fujii, J. Takada, R. Murakami, A. Doi, L. Anthony, Y. Ikeda and M. Takano, Chem. Mater., 16, 3641-3646 (2004).

9) Y. Kusano, T. Fujii, J. Takada, M. Fukuhara, A. Doi, Y. Ikeda and M. Takano, Chem. Mater., 20, 151-156 (2008).

10) Y. Kusano, A. Doi, M. Fukuhara, M. Nakanishi, T. Fujii, J. Takada, Y. Ikeda, M. Takano, C. Henrist, R. Cloots, A. Rulmont and M. Ausloos, J. Am. Ceram. Soc., 92, 1840-1844 (2009).

11) Y. Kusano, M. Fukuhara, J. Takada, A. Doi, Y. Ikeda and M Takano, Acc. Chem. Res., 43, 906-915 (2010).

12) A. Doi, T. Sakamoto, S. Tsutsumi, R. Otsuka and C. Kato, J. Chem. Soc. Jpn. Chem. Ind. Chem., 1, 71-75 (1979).

13) I. Miyagawa, "Glaze", Kyoritsu Shuppan Co., Ltd., Tokyo (1965) pp. 112.

14) H. Song and R. L. Coble, J. Am. Ceram. Soc., 73, 2077-2085 (1990).

15) H. Song and R. L. Coble, J. Am. Ceram. Soc., 73, 2086-2090 (1990).

16) A. P. Goswami, S. Roy, M. K. Mitra and G. C. Das, J. Am. Ceram. Soc., 84, 1620-1626 (2001).

17) X. Jin and L. Gao, J. Am. Ceram. Soc., 87, 533-540 (2004).

18) A. Muan and C. L. Gee, J. Am. Ceram. Soc., 39, 207-214 (1956). 